\title{
GEOCIÊNCIAS: UM ENSAIO PRELIMINAR DE AVALIAÇÃO E PERSPECTIVA
}

\author{
Saul B. SUSLICK
}

\begin{abstract}
RESUMO
O autor busca fornecer subsídios para um estudo avaliatório e prospectivo sobre diversos aspectos relacionados às Geociências em âmbito nacional e internacional. São abordados os impactos provocados pelas novas tecnologias, indicando que as Geociências, além de buscar a sua diversificação, devem também se preparar para a incorporação destas novas demandas em suas abordagens. Na parte final do trabalho são destacadas as principais tendências relacionadas ao futuro dos recursos minerais e à aplicação de Pesquisa e Desenvolvimento, com ênfase nas interfaces com as áreas emergentes do conhecimento.
\end{abstract}

\section{ABSTRACT}

The author attempts an evaluation and forecasting study on Earth Sciences in national and international scenarios. The impacts resulting from new technologies are discussed. The findings show that Geosciences beyond their current search for diversification, must also try to incorporate those new variables in their approach. The last section emphasizes the main trends related to the future of mineral resources and the use of Research and Development, associating them with emergent areas of knowledge.

\section{INTRODUÇÃO}

As Geociências têm um papel estratégico no contexto atual em função dos enormes desafios impostos neste final de década para compatibilizar as demandas oriundas do desenvolvimento econômico e do equilíbrio do meio físico. Sua contribuição é também significativa, pois a solução para diversas expectativas do homem repousa na previsão e no incremento do conhecimento sobre os desastres naturais, tais como secas, inundações, deslizamentos, erupções vulcânicas, terremotos e inclusive garantia de suprimento futuro de alimentos, água, energia e matéria-prima para a humanidade.

Este ensaio busca fornecer alguns subsídios sobre as Geociências no contexto nacional e internacional, priorizando uma reflexão e um estudo prospectivo e, ao mesmo tempo, avaliando qualitativamente o seu alcance e perspectivas para as próximas décadas.

Os aspectos quantitativos não foram enfatizados devido à dificuldade na obtenção de informações atualizadas e homogêneas sobre os diversos agentes (Universidades, Institutos de Pesquisa, Empresas, Organismos Governamentais etc...) do desenvolvimento científico e tecnológico em Geociências.

\section{ASPECTOS GERAIS DAS GEOCIÊNCIAS NO BRASIL}

Antes de adentrar na análise dos aspectos das Geociências no Brasil, vamos fazer uma breve descrição dos seus objetivos. As Geociências abrangem uma ampla área de conhecimento básico, envolvendo o estudo dos fenômenos que atuam na porção sólida da Terra (Litosfera), no seu envoltório líquido (Hidrosfera) e no ambiente gasoso que a cerca (Atmosfera). Em decorrência da interação e da enorme influência desempenhada pelos componentes biológicos no ambiente físico terrestre, os seres vivos não podem ser excluídos desse campo de atuação. Não escapa também do interesse das Geociências o conhecimento do sistema solar, pois a energia essencial para movimentar todos os processos físicos, químicos e biológicos que envolvem a Terra, tem a sua origem no Sol.

No tocante à sua aplicação, as Geociências no Brasil foram ligadas desde os seus primórdios à prospecção e estudo dos bens minerais, pois vêm contribuindo com insumos técnicos essenciais para o planejamento econômico, especialmente no que se refere à avaliação de matérias-primas minerais, de recursos energéticos e hídricos. Trata-se dos componentes que sempre desempenharam um papel estratégico para o desenvolvimento do País.

Mais recentemente as Geociências vêm contribuindo também para o planejamento da ocupação territorial e para a análise dos impactos antropogênicos, indo desde os acidentes naturais até as mudanças globais na Terra. Reconhece-se nessa nova tendência o interesse pela preservação do meio físico como um patrimônio natural 


\section{ANEXO 1}

\section{SIGLAS UTILIZADAS}

\begin{tabular}{|c|c|}
\hline CIID & $\begin{array}{l}\text { - Centro Internacional de Investi- } \\
\text { gações para o Desenvolvimento } \\
\text { (Canadá). }\end{array}$ \\
\hline CGMW & $\begin{array}{l}\text { - Commission for the Geological } \\
\text { Map of the World. }\end{array}$ \\
\hline CPRM & $\begin{array}{l}\text { - Companhia de Pesquisa de Re- } \\
\text { cursos Minerais. }\end{array}$ \\
\hline DNPM & $\begin{array}{l}\text { - Departamento Nacional da Pro- } \\
\text { dução Mineral. }\end{array}$ \\
\hline ICSU & $\begin{array}{l}\text { - International Council of Scien- } \\
\text { tific Unions. }\end{array}$ \\
\hline ICL & $\begin{array}{l}\text { - Inter-Union Commission on the } \\
\text { Lithosphere. }\end{array}$ \\
\hline IDNHR & $\begin{array}{l}\text { - International Decade for Natu- } \\
\text { ral Hazard Reduction. }\end{array}$ \\
\hline ILP & - International Lithosphere \\
\hline IGCP & $\begin{array}{l}\text { - International Geological Corre- } \\
\text { lation Program. }\end{array}$ \\
\hline
\end{tabular}

da humanidade, tão importante quanto os bens minerais.

Seria restringir demasiadamente a noção de Geociências considerá-la tão-somente afeita às questões de ordem espacial. De fato, importantes progressos vêm sendo conseguidos em setores mais ligados a campos analíticos e laboratoriais, onde integra com sucesso elementos de vanguarda de outras áreas afins do conhecimento científico nos campos da Física, da Química, da Informática e da Ciência dos Materiais.

De maneira análoga às ciências modernas, as Geociências comportam inúmeras subdivisões, a maioria delas bastante interfaceadas e imbricadas. Para facilitar o reconhecimento dos seus principais ramos, será adotada aqui a segmentação proposta pelo $\mathrm{CNPq}(1978,1982)$ :

Geologia: Abrange o estudo da Terra em sua totalidade, quanto à estrutura, composição e evolução. No estágio atual de desenvolvimento, o campo da Geologia apresenta diversas subáreas que já merecem o status de campos científicos independentes pelo nível e volume de conhecimento acumulados. Dentro destes campos (petrografia, sedimentologia etc...), os trabalhos são realizados em níveis variados, o que dificulta uma análise global e representativa da Geologia.

Geofísica: Estuda as propriedades físicas do Globo Terrestre e dos materiais geológicos e os processos físicos naturais da Terra, tanto na porção sólida como nos oceanos, atmosfera e magnetosfera.

\begin{tabular}{|c|c|}
\hline BP & $\begin{array}{l}\text { - International Geosphere- } \\
\text { Biosphere Programme - A Study } \\
\text { of Global Change. }\end{array}$ \\
\hline $\mathrm{C}$ & $\begin{array}{l}\text { - Intergovernmental Oceanographic } \\
\text { Commission. }\end{array}$ \\
\hline JGG & $\begin{array}{l}\text { nal Union of Geodesy } \\
\text { hysics. }\end{array}$ \\
\hline JGS & ion of Geological \\
\hline & $-\mathrm{M}$ \\
\hline & ional Technica \\
\hline NEP & $\begin{array}{l}\text { Nations Environment Pro } \\
\text { ne. }\end{array}$ \\
\hline UNESCO & $\begin{array}{l}\text { - United Nations Educational, Scien } \\
\text { tific and Cultural Organization. }\end{array}$ \\
\hline $\mathrm{FE}$ & - World Federation of Engineerin \\
\hline M & $\begin{array}{l}\text { - World Meteorological Orgar } \\
\text { zation. }\end{array}$ \\
\hline
\end{tabular}

Meteorologia: Estuda a atmosfera terrestre, os processos físicos e dinâmicos que nela se desenvolvem e sua interação com a crosta terrestre e a hidrosfera.

Geodésia: Estuda as formas e dimensões da Terra através da determinação dos parâmetros do campo de gravidade, proporcionando apoio ao levantamento cartográfico sistemático da Terra.

Geografia Física: Estuda, de forma integrada, o meio físico da Terra que analisa as características dos componentes dos processos e das relações existentes neste sistema. A Geografia Física integra tradicionalmente os campos da Geomorfologia, Climatologia, Hidrologia, Biogeografia e Geografia dos Solos.

Nas décadas de 70 e 80 as Geociências no Brasil experimentaram um grande desenvolvimento em termos quantitativos em todas as suas áreas. O crescimento do número de pesquisadores e a distribuição dos núcleos de pesquisa em diferentes regiões do País demonstram a necessidade de políticas de fomento integradas para essa área estratégica.

Conforme apontado, as Geociências abrangem um espectro extenso e variado de atividades científicas e tecnológicas, envolvendo pesquisadores com uma formação profissional bastante diferenciada, ou seja, geólogos, engenheiros, geógrafos, físicos, químicos, meteorologistas, naturalistas, ecólogos e outros. Em função 
dessa peculiaridade é bastante difícil traçar um perfil único para essa área de conhecimento, na medida que os setores possuem evolução heterogênea e, em algumas situações, extremamente desigual.

Além das universidades, várias instituições governamentais desenvolvem investigações de caráter aplicado em Geociências, destacando-se a Petrobrás (Cenpes), CPRM/DNPM, CVRD, empresas, entidades do Sistema Estadual de Mineração (Metago, CBPM, Comig, etc...), Instituto Geológico, Cetem, Cetec, IPT, Ceped e outros. A maioria dessas instituições apresenta projetos de pesquisa específicos, sem programas sistemáticos de aperfeiçoamento e especialização de pessoal, exceto algumas iniciativas de caráter episódico e pontuais. Cumpre mencionar o importante papel desempenhado pela Petrobrás no treinamento dos seus técnicos através dos diversos programas desenvolvidos com instituições universitárias brasileiras e internacionais.

$\mathrm{Na}$ área tecnológica existe um bom potencial que pode, num curto espaço de tempo, incrementar ainda mais a capacitação interna na resolução dos problemas ligados à Tecnologia Mineral e na aplicação das Geociências, embora o número de doutorados especificamente na primeira área seja muito reduzido.

Ainda devem ser mencionadas as empresas de projetos e consultoria e as empresas fornecedoras de equipamentos de mineração e instrumentação em geral, ressaltando que algumas vêm recebendo apoio por parte dos organismos de fomento.

Nos campos da graduação e da pós-graduação permanece ainda a disparidade regional na capacitação para ensino e pesquisa apontada nos documentos "Avaliação \& Perspectivas"' (CNPq 1978, 1982), SBG (1982) e CORDANI et al. (1987), onde algumas dispõem de bons grupos de pesquisa e outras enfrentam muitas dificuldades para organizar núcleos efetivos ou emergentes. Dificuldades de toda ordem vão desde a valorização salarial dentro dos quadros das instituições universitárias, aumento do número de bolsas, apoio mais decisivo do governo aos levantamentos geológicos básicos até a melhoria da infraestrutura técnico-administrativa das universidades e centros de pesquisa.

$\mathrm{O}$ crescimento do número de pesquisadores é muito pequeno frente às reais necessidades do País nesta área. $\mathrm{O}$ número de doutores nos diferentes setores das Geociências é ainda incipiente se comparado com os índices internacionais. Deve-se também buscar estímulos para a absorção imediata de pesquisadores recémdoutorados.

\section{GEOCIÊNCIAS NO CONTEXTO INTERNACIONAL}

A sociedade moderna busca, através da Ciência e da Tecnologia, soluções para seus grandes desafios. As Geociências, por meio de seu caráter interdisciplinar, podem contribuir grandemente para atender expectativas como prevenção de acidentes naturais, tais como estiagens, inundações, deslizamentos, subsidiências, erupções vulcânicas e terremotos, dentre outros. Pode-se até afirmar que as Geociências poderão fornecer o termômetro para se aferir os limites em que a Natureza será tolerante com a interferência do Homem em escala local, regional ou global.

O homem tornou-se um fator geológico e deve preparar-se adequadamente para enfrentar esse novo status. Um exemplo dessa afirmativa é o fato de cada indivíduo no mundo industrializado utilizar anualmente em média 20 toneladas de matérias-primas minerais (McDIVITT \& MANNERS, 1974). A Figura 1 ilustra a diversidade de materiais consumidos pela sociedade moderna. Segundo CALLOT (1985), o valor da produção mineral mundial em 1983 pode ser estimado em 930 bilhões de dólares, responsável pelo consumo de 7 bilhões de toneladas/ano oriundas de um grande número de espécies minerais.

Neste contexto, os governos, as associações científicas e os organismos internacionais vêm desenvolvendo inúmeros programas para proporcionar condições de estudo desses fenômenos e seus impactos. A Tabela 1 apresenta os principais programas internacionais na área de Geociências que abrangem a América do Sul. A seguir passaremos a resumir os principais projetos internacionais nesta área.

A Unesco possui dois grandes programas dedicados às Geociências: "The Earth's Crust and its Mineral and Energy Resources" e um segundo que trata do estudo dos grandes acidentes naturais (SIBRAVA, 1987). No primeiro grupo estão incluídos o IGCP "'International Geological Correlation Program,', o projeto regional denominado "Geology from Development", a disseminação de dados geológicos e um projeto de formação de recursos humanos em países do Terceiro Mundo. O orçamento anual que a Unesco destina à Divisão das Ciências da Terra, responsável por estes projetos, é aproximadamente de US\$ 10 milhões, sendo 37 destinados ao IGCP, $25 \%$ para o Programa de Acidentes Naturais e o restante distribuído entre as demais atividades.

O IGCP, criado em 1961 conjuntamente pela UNESCO eIUGS, pode ser considerado o 


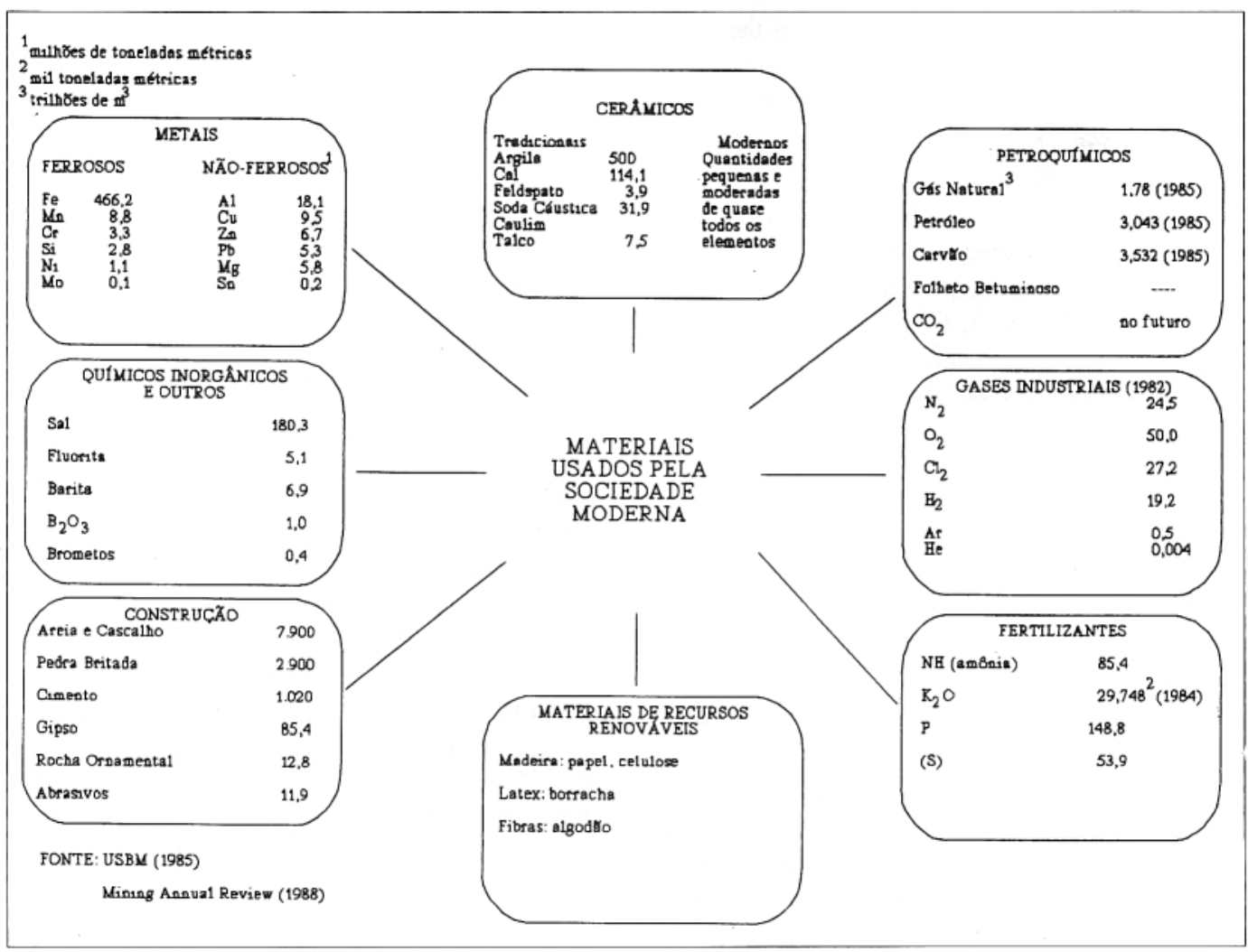

FIGURA 1 - Demanda mundial de materiais (milhões de toneladas curtas, exceto quando especificada outra unidade).

programa de cooperação científica internacional de maior sucesso nas ciências geológicas. Ele abrange uma temática bastante ampla: estratigrafia, paleontologia, geoquímica, geologia econômica, métodos laboratoriais, informática e sensoriamento remoto. Cerca de dois mil pesquisadores de 83 países participam do projeto. Em 1987, a direção do IGCP criou um novo subprograma denominado "Quaternary Geosciences and Human Survival', que focalizará o seu interesse no estudo do Quaternario e seus efeitos na geologia econômica, agricultura, estudos paleoclimáticos e previsão das mudanças climáticas e ambientais.

Um outro grande programa de caráter multi e interdisciplinar que merece destaque é o IGBP ("International Geosphere-Biosphere Programme: A Study of Global Change"), que visa estudar as transformações progressivas no meio ambiente, identificando suas causas, naturais ou antropogênicas, realizando previsões de longo prazo das possibilidades futuras de habitabilidade na Terra e investigando as alternativas para minimizar esses efeitos (PRICE, 1986). Trata-se de um programa de ciência fundamental, que abrange grande parte das Geociências (Meteorologia, Oceanografia, Hidrologia, Geologia, Geoquímica, Geofísica, entre outras) envolvendo a dinâmica de todo o sistema Terra: os oceanos, o solo/subsolo, a atmosfera, o clima e a pequena camada de sua superfície denominada biosfera.

É um grande desafio para a comunidade científica internacional, que provavelmente se estenderá para o próximo milênio. O comitê do IGBP criou quatro linhas de pesquisa que constituem a base científica do programa:

a) Documentação e Previsão da Mudança Global - Consiste na coleta e análise dos dados com o objetivo de identificar os processos naturais e os efeitos das transformações globais. A natureza e a extensão das mudanças pretéritas serão incorporadas em modelos previsionais que incluirão as relações entre os processos biogeoquímicos e os sistemas físicos e climáticos, bem como informação disponível sobre os impactos antropogênicos atuais e medidas preventivas.

b) Conhecimento das Funções das Forças Predominantes - Os efeitos das forças externas, das mudanças orbitais, do sistema solar, dos processos da Terra Sólida e das atividades humanas constituem elementos fundamentais da mudança global (Figura 2). As pesquisas nesta área incluem a investigação do significado e da magnitude das forças externas provocadas pelas variações solares e orbitais e os fenômenos terrestres, o conhecimento das forças naturais de- 
TABELA 1 - Principais programas internacionais na área de Geociências.

\begin{tabular}{|c|c|c|c|}
\hline NOME DO PROGRAMA & ENTIDADE & Ano & TEMÁTICA \\
\hline $\begin{array}{l}\text { IGCP - International Geol. } \\
\text { Correlation program }\end{array}$ & UNESCO, IUGS & 1961 & $\begin{array}{l}\text { abrange grande parte da área das } \\
\text { Geociências }\end{array}$ \\
\hline Geology for Economic Development & UNESCO & 1980 & $\begin{array}{l}\text { estudo do Pré-Cambriano da África } \\
\text { por Geotransversais }\end{array}$ \\
\hline $\begin{array}{l}\text { Disseminação de Dados Geológicos } \\
\text { - Geology and Environment } \\
\text { - Geological Application of Remote } \\
\text { Sensing (GARS) }\end{array}$ & $\begin{array}{l}\text { UNESCO } \\
\text { UNESCO, USP } \\
\text { UNESCO, IUGS }\end{array}$ & $\overline{1984}$ & $\begin{array}{l}\text { planej. territorial e hidrológico } \\
\text { estudos de sensoriamento remoto } \\
\text { áreas tropicais (África/A. Latina) }\end{array}$ \\
\hline Mapas Geológicos & UNESCO, CGMW & - & $\begin{array}{l}\text { elaboração de mapas: Mapa Geológico } \\
\text { do Mundo, Mapa Geológ. A. do Sul } \\
(1: 5.000 .000)\end{array}$ \\
\hline $\begin{array}{l}\text { Program on Ocean Sciences in } \\
\text { Relation to Non-Living Resources }\end{array}$ & UNESCO, IOC & - & $\begin{array}{l}\text { recursos do mar, geologia marinha e } \\
\text { estudos de mudanças ambientais nos } \\
\text { oceanos }\end{array}$ \\
\hline $\begin{array}{l}\text { International Geosphere-Biosphere } \\
\text { Program: A Study of Global Change } \\
\text { - IGBP }\end{array}$ & ICSU & 1986 & $\begin{array}{l}\text { programa multidisciplinar visando } \\
\text { descrever a interação dos processos } \\
\text { que regulam a }\end{array}$ \\
\hline $\begin{array}{l}\text { International Decade for Natural } \\
\text { Hazard Reduction - IDNHR } \\
\end{array}$ & $\begin{array}{l}\text { ICSU, WFED, } \\
\text { UITA }\end{array}$ & 1990 & $\begin{array}{l}\text { redução dos impactos dos acidentes } \\
\text { naturais potenciais nos ambientes sociais }\end{array}$ \\
\hline $\begin{array}{l}\text { Programa Internacional da Litosfera } \\
\text { (ILP) } \\
\text { - Projeto Global das Transversais }\end{array}$ & $\begin{array}{l}\text { IUGS, ICL } \\
\text { IUGG }\end{array}$ & - & $\begin{array}{l}\text { conhecimento das estruturas da } \\
\text { litosfera }\end{array}$ \\
\hline $\begin{array}{l}\text { Programa de Ciências da Terra } \\
\text { - Hidrogeologia/Hidrologia } \\
\text { - Pequena Mineração } \\
\text { - Geotécnica, Geologia Geral, } \\
\text { Geofísica e Geoquímica Aplicada. }\end{array}$ & CIID & 1985 & $\begin{array}{l}\text { ampla variedade de tópicos, alguns } \\
\text { com fortes componentes geotécnicos, } \\
\text { hidrogeologia urbana e insumos } \\
\text { minerais industriais. }\end{array}$ \\
\hline
\end{tabular}

Fonte: Dados compilados pelo autor. Ver siglas no Anexo I.

vidas às perturbações transitórias no sistema terrestre e as forças antropogênicas atribuídas às mudanças na composição química da atmosfera, no aproveitamento do solo/subsolo e da água.

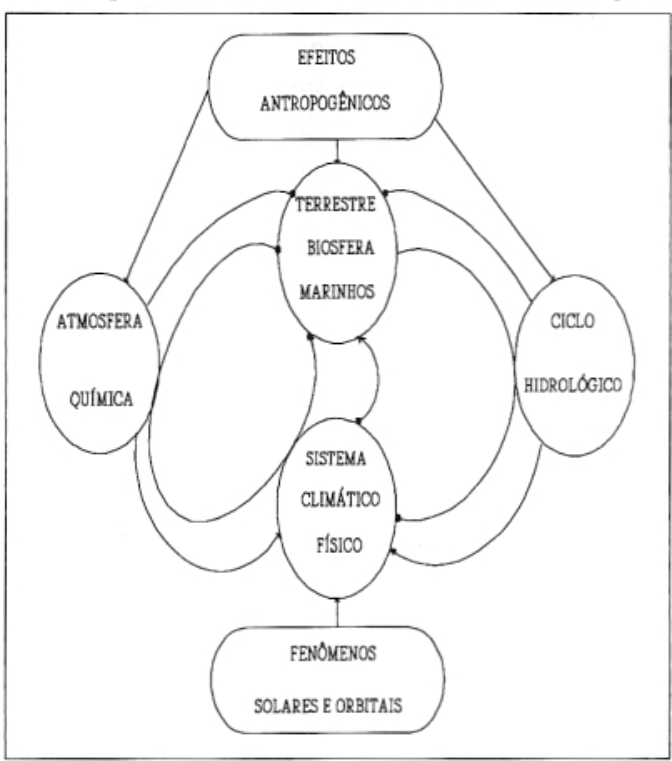

FIGURA 2 - Esquema ilustrativo das forças responsáveis pelas mudanças globais.

Fonte: Adaptado de IUGS (1988) c) Conhecimento dos Fenômenos Interativos no Sistema Terra - As interações na Terra, principalmente as respostas biológicas às transformações físico-químicas no ambiente, são tipicamente não-lineares. As mudanças climáticas projetadas para o futuro podem estar além da capacidade de adaptação de diversos organismos. Nesse sentido estão previstas as seguintes etapas: desenvolvimento do processo das interações não-lineares entre os componentes físicoquímicos e biológicos do sistema através de modelagem e quantificação potencial dessas interações.

d) Avaliação dos Efeitos da Mudança Global na Disponibilidade dos Recursos Renováveis e Não-Renováveis - Nesta etapa estão previstos os estudos de regiões suscetíveis às mudanças bruscas devido à interferência do homem na exploração dos recursos terrestres. Será enfocada também a utilização dos conhecimentos adquiridos no controle e prevenção desses efeitos em escala regional.

Os estudos dos acidentes naturais através do programa IDNHR ("International Decade for Natural Hazard Reduction"'), organizado pelo ICSU, constitui também outro grande programa 
que deve concentrar os esforços de diversas instituições internacionais e de grande importância para o contexto brasileiro. Nas duas últimas décadas registraram-se 2,8 milhões de mortes provocadas por acidentes naturais (furacões, inundações, deslizamentos, estiagens, atividades vulcânicas etc...) que afetaram 820 milhões de pessoas no mundo (Tabela 2). Além das perdas de vidas humanas, um único acidente pode atingir dezenas de grandes obras civis, com sérios impactos nas atividades econômicas e sociais. Estima-se que nos últimos 20 anos os prejuízos alcançaram a cifra de US\$ 100 bilhões.

Independentemente de suas fronteiras geopolíticas, a maioria dos países é suscetível a esses desastres. Exemplos nacionais são bastante significativos nas condições do nosso contexto do meio tropical, como os deslizamentos no Rio de Janeiro e Caraguatatuba e as enchentes freqüentes nas regiões Sul e Sudeste. Permanece como grande desafio a criação de mecanismos para a diminuição dos impactos potenciais desses eventos nos ambientes sociais e construtivos. O comitê do IDNHR fez as seguintes recomendações para as instituições interessadas neste tema para a próxima década:

a) Estabelecer o período de 1990-2000 como a Década Internacional para a Redução dos Acidentes Naturais através das seguintes atividades: coleta de experiências e práticas na diminuição dos acidentes e identificação das lacunas atuais do conhecimento sobre o tema; acelerar as aplicações e novas abordagens e incrementar o conhecimento científico e de engenharia que oferece melhoria substancial nas práticas de mitigar os efeitos das catástrofes;

b) Todas as nações devem ser incentivadas a participar do IDNHR, incluindo tanto as que sofrem constantemente os efeitos desses desastres como aquelas que podem contribuir para a sua minimização;

c) As Nações Unidas devem promover e facilitar o IDNHR, contando com ampla participação não somente da comunidade científica mas também das demais instituições envolvidas com a questão, de modo a formular seu plano de ação no menor prazo possível.

A cooperação técnica internacional é essencial na área de Geociências devido às peculiaridades de interligação de campos distintos e à possibilidade de treinamento e intercâmbio com pesquisadores estrangeiros dentro dos projetos acima mencionados e de outros de interesse mais restrito à realidade brasileira.

Infelizmente, o intercâmbio técnicocientífico internacional é muito incipiente mesmo quando as instituições possuem interesses co- muns. Essa limitação vem inibindo a adequada geração, difusão e absorção dos conhecimentos, bem como a utilização de novas tecnologias de setores emergentes como Informática, Novos Materiais etc.

Atualmente existe uma tendência internacional para aglutinação em torno dos grandes programas interdisciplinares acima relacionados (SEIBOLD, 1985). Esse fato provoca uma ação catalisadora no desenvolvimento científico em diversas áreas das Geociências. Entretanto, existem alguns campos ou "pesquisas marginais" de interesse dos países do Terceiro Mundo que não são suscetíveis a essa nova onda internacional, mas que devem continuar recebendo tratamento especial por parte dos organismos de fomento, como, por exemplo, as pesquisas relativas aos problemas do meio físico tropical.

\section{NECESSIDADES E POSSIBILIDADES DA SOCIEDADE BRASILEIRA}

$\mathrm{O}$ aproveitamento dos recursos minerais sempre atraiu a atenção das Geociências e vem desempenhando um importante papel em diversos momentos da vida nacional. No cenário internacional, o Brasil representa na atualidade um importante exportador de grande número de "commodities minerais". Destacou-se em 1989 como primeiro produtor mundial de nióbio e cassiterita, contribuindo aproximadamente com $82 \%$ e $22,7 \%$ do total produzido respectivamente; é o segundo maior produtor de minério de ferro, atingindo $16,4 \%$ da produção do Mundo Ocidental; ocupa o terceiro lugar na produção de bauxita com aproximadamente $9 \%$ e detém a quarta posição na produção de manganês $(7,3 \%)$, destacando-se também como um grande produtor mundial de tantalita $(30 \%)$.

$\mathrm{Na}$ área dos metais preciosos, o Brasil vem assumindo posições de destaque na produção de ouro $(5,4 \%)$, ficando somente atrás da África do Sul, Austrália, EUA e Canadá. Dados do DNPM (1990) indicam que o Brasil possui a primeira reserva mundial de nióbio $(86,9 \%)$, a segunda em barita $(15,2 \%)$, a terceira em bauxita $(10,2 \%)$, cassiterita $(14,4 \%)$ e quinta posição em ferro $(8,6 \%)$ e magnesita $(7 \%)$.

Apesar do crescimento da produção mineral brasileira, o País continua dependente de fontes externas em petróleo, carvão, enxofre, potássio, entre outros, para o abastecimento de seu parque industrial, o que onera sobremaneira a pauta de importações da balança mineral brasileira.

Segundo SUSLICK et al. (1988), o Brasil no contexto sul-americano continua despontando com o maior valor de produção mineral do 
TABELA 2 - Principais acidentes naturais do Século XX.

\begin{tabular}{|c|c|c|c|}
\hline ANO & EVENTO & LOCALIZAÇÃO & MORTOS \\
\hline 1900 & Furacão & EUA & 6.000 \\
\hline 1902 & Vulcanismo & Martinica & 29.000 \\
\hline 1902 & Vulcanismo & Guatemala & 6.000 \\
\hline 1906 & Tufão & Hong Kong & 10.000 \\
\hline 1906 & Terremoto & Taiwan & 6.000 \\
\hline 1906 & Terremoto/Fogo & EUA & 1.500 \\
\hline 1908 & Terremoto & Itália & 75.000 \\
\hline 1911 & Vulcanismo & Filipinas & 1.300 \\
\hline 1915 & Terremoto & Itália & 30.000 \\
\hline 1916 & Deslizamentos & Itália/Áustria & 10.000 \\
\hline 1919 & Vulcanismo & Indonésia & 5.200 \\
\hline 1920 & Terremoto/Deslizamento & China & 200.000 \\
\hline 1923 & Terremoto/Fogo & Japão & 143.000 \\
\hline 1928 & Furacão/Inundação & EUA & 2.000 \\
\hline 1930 & Vulcanismo & Indonésia & 1.400 \\
\hline 1932 & Terremoto & China & 70.000 \\
\hline 1933 & Tsunami & Japão & 3.000 \\
\hline 1935 & Terremoto & Índia & 60.000 \\
\hline 1938 & Furacão & EUA & 600 \\
\hline 1939 & Terremoto/Tsunami & Chile & 30.000 \\
\hline 1945 & Inundação/Deslizamento & Japão & 1.200 \\
\hline 1946 & Tsunami & Japão & 1.400 \\
\hline 1948 & Terremoto & URSS & 100.000 \\
\hline 1949 & Inundação & China & 57.000 \\
\hline 1949 & Terremoto/Deslizamento & URSS & 20.000 \\
\hline 1951 & Vulcanismo & Papua Nova Guiné & 2.900 \\
\hline 1953 & Inundação & Europa (Mar do Norte) & 1.800 \\
\hline 1954 & Deslizamentos & Áustria & 200 \\
\hline 1954 & Inundação & China & 40.000 \\
\hline 1959 & Tufão & Japão & 4.600 \\
\hline 1960 & Terremoto & Marrocos & 12.000 \\
\hline 1961 & Tufão & Hong Kong & 400 \\
\hline 1962 & Deslizamentos & Peru & 5.000 \\
\hline 1962 & Terremotos & Irã & 12.000 \\
\hline 1963 & Ciclone Tropical & Bangladesh & 22.000 \\
\hline 1963 & Vulcanismo & Indonésia & 1.200 \\
\hline 1963 & Deslizamentos & Itália & 2.000 \\
\hline 1965 & Ciclone Tropical & Bangladesh & 57.000 \\
\hline 1967 & Inundação & Brasil (leste) & 1.000 \\
\hline 1968 & Terremoto & Irã & 12.000 \\
\hline 1970 & Terremoto/Deslizamento & Peru & 70.000 \\
\hline 1970 & Ciclone Tropical & Bangladesh & 500.000 \\
\hline 1971 & Ciclone Tropical & Índia & 25.000 \\
\hline 1976 & Terremoto & China & 250.000 \\
\hline 1976 & Terremoto & Guatemala & 24.000 \\
\hline 1976 & Terremoto & Itália & 900 \\
\hline 1977 & Ciclone Tropical & Índia & 20.000 \\
\hline 1978 & Terremoto & Irã & 25.000 \\
\hline 1982 & Vulcanismo & México & 1.700 \\
\hline 1985 & Ciclone Tropical & Bangladesh & 10.000 \\
\hline 1985 & Terremoto & México & 10.000 \\
\hline 1985 & Vulcanismo & Colômbia & 22.000 \\
\hline 1987 & Incêndio & China & 200 \\
\hline 1988 & Inundações/Deslizamentos & Brasil & 400 \\
\hline
\end{tabular}

Fonte: International Decade For Narural Hazard Reduction (IDNHR), A Summary IUGS, 1988. Dados compilados pelo autor. 
TABELA 3 - Densidades de produção mineral - minerais não energéticos (1983).

\begin{tabular}{l|c|c|c|c}
\cline { 2 - 5 } \multicolumn{1}{c|}{ PAÍ́ } & \multicolumn{3}{c|}{ PRODUÇÃO } & valor da prod./PNB \\
\hline Argentina & US\$ milhões (1983) & US\$/ $\mathrm{km}^{2} *$ & US\$/hab** & US\$/US\$ \\
Bolívia & 123,6 & 45 & 4,2 & 0,21 \\
Brasil & 434,1 & 395 & 71,4 & 14,14 \\
Chile & $3.215,1$ & 378 & 24,8 & 1,29 \\
Colômbia & $2.340,8$ & 3.093 & 200,4 & 10,67 \\
Guiana & 300,0 & 263 & 10,9 & 0,77 \\
Peru & 47,0 & 219 & 51,1 & 11,50 \\
Suriname & $1.599,5$ & 1.245 & 85,5 & 8,56 \\
Venezuela & 128,5 & 787 & 367,1 & 10,00 \\
& 247,5 & 271 & 15,1 & 0,35 \\
América Latina & $10.978,7$ & 483 & 28,9 & 15,34 \\
EUA & $9.544,2$ & 1.019 & 40,7 & 1,04 \\
África do Sul & $11.955,0$ & 9.791 & 388,1 & 15,53 \\
Mundo & $85.577,5$ & 633 & 18,3 & 7,71 \\
& & & & 4,67 \\
PEM & $38.318,5$ & 1.149 & 47,6 & 8,22 \\
PEP & $25.927,9$ & 725 & 17,1 & 10,23 \\
PVD & $21.321,6$ & 319 & 9,1 & \\
\hline
\end{tabular}

PEM: Países de Economia de Mercado = África do Sul, USA/Canadá, Japão, Europa Ocidental e Oceania. PEP: Países de Economia Planificada $=$ Ásia Comunista, Europa Oriental e URSS.

PVD: Países em vias de desenvolvimento = América Central e do Sul, África outros e Ásia outros.

* valores em milhões de dólares (valores constantes - 1983) e a superfície em milhões de $\mathrm{km}^{2}$.

** valores em milhões de dólares e milhões de habitantes.

Fonte: Anales des Mines (1985)

Mineral Yearbook (1985)

IG/UNICAMP (1988)

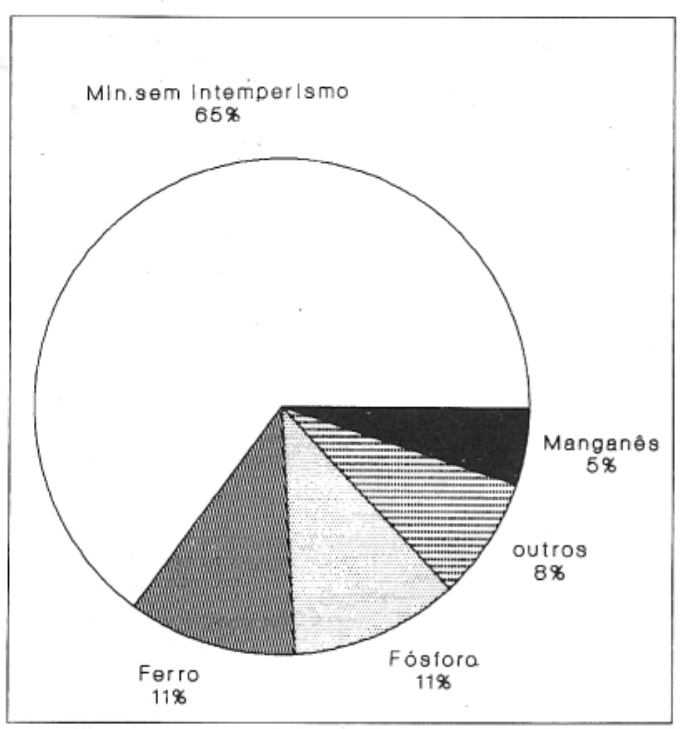

FIGURA 3 - Pesquisa científica e tecnológica nas instituições: 1975-1983.

Fonte: Lastres et al. (1983).

Continente, embora Chile, Peru, Bolívia, Guiana e Suriname apresentem densidades de produção por habitante, por km2 e participação no PNB (Produto Nacional Bruto) bastante superiores (Tabela 3). Apesar das estimativas terem si- do realizadas pelos autores com dados de produção e PIB de 1983, esses valores se mantiveram constantes durante toda a década.

Dentro deste contexto, a componente de ciência e tecnologia tem um papel estratégico tanto no aproveitamento racional dos recursos minerais como na produção de bens de maior valor agregado. No campo mineral não se pode simplesmente operar em transferência de tecnologia, tal como na indústria de transformação, na medida que o desenvolvimento de técnicas e estudos deve ser ajustado às características de cada jazida. Convém salientar que uma substância mineral não é por si só uma matéria-prima, pois é necessário que, após a identificação dos minerais econômicos (ou valiosos), sejam aplicados os estudos tecnológicos para transformar uma substância mineral em produto comercializável.

Os efeitos produzidos pelo modelo exportador da década de 70 , baseado fundamentalmente em tecnologias importadas, são notáveis na implantação de altos fornos siderúrgicos que operam com carvão de baixo teor de enxofre e cinzas, acentuando a dependência da indústria nacional de matéria-prima importada. Dados levantados por LASTRES et al. (1983), referentes ao período de 1975 a 1983, indicam que $65 \%$ dos 
projetos executados pelos centros de pesquisas tecnológicas brasileiras envolveram minérios de jazimentos primários (Figura 3).

Uma análise superficial mostra a importância estratégica das jazidas de intemperismo, típicas dos países de clima tropical como o Brasil, que permitem a produção de nióbio, fosfato, bauxita, anatásio, caulim etc., a partir de minérios de origem supérgena. Por diversas razões, que não cabe analisar neste trabalho, o desenvolvimento de tecnologias orientadas para o aproveitamento destes minerais foi relegado a um plano secundário.

No contexto da pesquisa geológica básica destacam-se os levantamentos geológicos básicos (LGBs) que constituem, segundo a SBG (1985), a base do conjunto de informações e conhecimentos providos pelo Estado à sociedade para atender, em qualidade e quantidade, as necessidades do aproveitamento racional e harmônico do solo e subsolo do País e o permanente avanço do conhecimento técnico-científico em Geociências.

A disponibilidade do conhecimento geológico em mapas com escalas adequadas, em textos e sistemas informáticos associados, representa o produto dos LGBs. Entretanto, a despeito dos benefícios decorrentes do conhecimento geológico, em termos sócio-econômicos e geoambientais, observa-se que os investimentos após 1978 caíram drasticamente atingindo em 1984 os patamares de 1970 (SBG, 1985).

Recentemente, o sistema CPRM/DNPM visando atender às reivindicações das entidades do setor mineral (SBG, Ibram, Abemin, Conage e Faemi) retomou o Programa de Levantamentos Geológicos Básicos do Brasil (PLGB) no qual são previstos até 1999 (DNPM, 1985) os seguintes produtos:

a) cobertura aerogeofísica de áreas précambrianas da Amazônia num total de $1.404 .000 \mathrm{~km}^{2}$;

b) mapeamento geológico e geoquímico na escala de 1:250.000 nas áreas pré-cambrianas da Amazônia selecionadas pela aerogeofísica num total de $2: 100.000 \mathrm{~km}^{2}$;

c) mapeamento geológico e geoquimico na escala 1:100.000 fora da Região Amazônica num total de cerca de $2.400 .000 \mathrm{~km}^{2}$ e na escala de 1:50.000 em cerca de $980.000 \mathrm{~km}^{2}$;

d) elaboração de mapas metalogenéticos e de previsão de recursos minerais em 1:250.000 em cerca de $3.600 .000 \mathrm{~km}^{2}$ da área précambriana;

e) cobertura de cerca de $120.000 \mathrm{~km}^{2}$ do país com mapas de recursos hídricos subterrâneos, com prioridade para o Nordeste.
Os recursos destinados em 1986 e 1987 para o PLGB foram da ordem de 21 milhões e 50 milhões de dólares respectivamente. Apesar de significativos no período, este montante é muito aquém da demanda efetiva e do ritmo de levantamentos básicos almejado pela sociedade brasileira.

Deve-se mencionar ainda que o novo texto constitucional proporcionou a criação de um Serviço Geológico Nacional, que deverá ser complementado obviamente por atividades regionais. A aglutinação da atual capacidade técnicoadministrativa numa instituição desta natureza trará muitos benefícios não somente para a mineração como para o progresso do conhecimento do meio físico brasileiro. Sem o conhecimento da potencialidade do subsolo e suas áreas correlatas será difícil executar uma gestão e ocupação responsável e muito menos induzir a aplicação de recursos privados para uma atividade de alto risco e de demorado retorno do capital investido, como é a mineração.

\section{EMERGÊNCIA DE NOVAS DISCIPLINAS}

De maneira análoga aos demais ramos da ciência, o desenvolvimento das Geociências vem sendo bastante influenciado pela incorporação de novos métodos è equipamentos. Exemplos são marcantes na Geodésia e nas aplicações de sensoriamento remoto através de satélites artificiais, que têm possibilitado grandes sucessos no reconhecimento da estrutura e do material do subsolo com maior precisão e em grandes profundidades na crosta.

Os mesmos avanços atingidos pela tomografia computadorizada nas áreas biomédicas poderão ser utilizados, guardadas as devidas proporções, na tomografia das massas e correntes oceânicas. Os novos métodos instrumentais empregados com sucesso na Ciência dos Materiais encontrarão grande utilidade para análise dos materiais geológicos, aumentando o seu nível de aproveitamento e prolongando a vida útil das jazidas minerais. Isso certamente acabará beneficiando toda a sociedade.

A tendência das Geociências nos países desenvolvidos caminha no sentido da diversificação e incorporação destas novas tecnologias. Por outro lado, no bloco de países do Terceiro Mundo persiste ainda uma forte ênfase na busca e exploração de minérios destinados unicamente à exportação (DENGO, 1988), com resultados nem sempre positivos para as economias de certos países.

Esta nova orientação não implica que os pesquisadores das Geociências devam abandonar os recursos minerais, que trazem benefícios sociais 
e econômicos sob uma gestão racional, mas existem outros horizontes que podem também ser contemplados, tais como: planejamento urbano e territorial, uso e ocupação do solo, gestão de recursos hídricos, estudos do meio físico, entre outras áreas.

A questão da emergência de novas disciplinas e da transdisciplinaridade em Geociências implica um esforço de cooperação entre geólogos, engenheiros, geógrafos, geofísicos, cientistas dos materiais e outros profissionais no sentido de romper fortes condicionamentos culturais que marcam a evolução nas diversas áreas do conhecimento. A título de um exercício prospectivo podemos enfocar alguns setores importantes que merecem destaque:

a) Aplicações Ambientais: Trata-se de uma área que vem recebendo grande atenção a nível nacional e internacional conforme ressaltado anteriormente. Estas atividades são de cunho eminentemente interdisciplinar e visam à proteção ambiental e à melhor gestão dos recursos naturais pelo homem. As Geociências são essenciais em qualquer estudo ambiental, principalmente nas condições tropicais. Apesar dos sensíveis avanços alcançados no Brasil pelas instituições de pesquisa, necessita-se de ações de interação e intercâmbio com os demais setores da ciência interessados na proteção e monitoramento ambiental. As principais áreas emergentes neste campo seriam as seguintes:

- Geoquímica Ambiental: Preparação de atlas geoquímicos para reconhecimento dos elementos químicos dispersos nos diferentes meios;

- Geologia e Saúde Pública: Estudo das relações entre a composição solo/ar/água e a distribuição geográfica das doenças. Os exemplos são inúmeros, como a contaminação de mercúrio em garimpos de ouro, fluoretos e problemas dentários, efeitos da qualidade da água, etc. $\mathrm{Na}$ URSS foram estudadas correlações entre a geologia local e a ocorrência de certos tipos de câncer;

- Planejamento Geoambiental e seus efeitos associados ao uso e ocupação do solo. Nesta linha de pesquisa as disciplinas, como geomorfologia, geologia de engenharia etc..., teriam uma importante contribuição nessa área;

b) Agrogeologia - Aplicações do conhecimento dos materiais geológicos no incremento da fertilidade do solo.

c) Mineralogia e os Materiais - Aplicação do desenvolvimento moderno dos métodos analíticos em interação com a física e a ciência dos materiais. Na medida em que o Brasil é detentor de enorme potencialidade mineral, algumas substâncias poderiam ter seu grau de aproveitamento incrementado graças a uma melhor caracterização tecnológica (mineralogia e química fina mineral) e uma forte interação entre geólogos, químicos, engenheiros e demais especialistas;

d) Tecnologia de Minerais Industriais Existe uma gama enorme de minerais que ainda permanece pouco utilizada pela indústria e merece destaque nos países em desenvolvimento dado o seu nível de reservas e seu efeito multiplicador em diversos setores econômicos. Exemplo: argilas especiais, vermiculitas etc.. Esta área contemplaria a pesquisa de novos usos, agregação de valor, entre outros aspectos, na medida em que esta disciplina estaria fortemente influenciada pela área de materiais;

e) Interação Atmosfera/Geosfera (Oceano) $\mathrm{O}$ impacto das trocas de energia da atmosfera e a dinâmica da circulação oceânica ocorrem sob a forma de importantes alterações climáticas que necessitam de um maior nível de entendimento e interação de diferentes áreas.

f) Sistemas Especialistas - O desenvolvimento destes sistemas para a área de Geociências é de suma importância por diferentes motivos: auxílio na descoberta de novos depósitos minerais, possibilidades de interação com outras áreas e facilidade no tratamento e incorporação de grande volume de dados existentes;

g) Instrumentação - Trata-se de um campo de pesquisa bastante promissor, pois todas atividades de pesquisa em Geociências exigem a utilização de equipamentos e o progresso em inúmeras áreas está condicionado ao desenvolvimento da instrumentalização;

h) Modelagem de Processos Naturais - O avanço na simulação e na modelagem computacional ou física dos fenômenos naturais permite antever grandes progressos nesta área, com desdobramentos imediatos em prospecção mineral, explotação de reservatórios de petróleo e na compreensão da dinâmica dos acidentes naturais.

i) Estudo do Caos e dos Fractais - Diversos pesquisadores vêm buscando correlacionar algumas estruturas geológicas com a dimensão fractal visando aprofundar os conhecimentos dos processos geológicos.

\section{PRINCIPAIS TENDÊNCIAS}

Em função do próprio ritmo de evolução das Geociências, as áreas do conhecimento apresentam um desenvolvimento desigual em decorrência de fatores econômicos (p. ex.: petróleo), da dinâmica de setores específicos (mineração), da incorporação de novas tecnologias (p. ex.: sensoriamento remoto, geocronologia) e de eventuais interfaces com áreas emergentes (acidentes naturais, novos materiais etc.). Estas especificida- 
des tornam bastante difícil delinear as tendências em Geociências. Como um pequeno exercício pode-se identificar alguns horizontes em P\&D e em áreas que já sinalizam uma evolução como os recursos minerais e energéticos.

\subsection{Recursos minerais}

A indústria mineral mundial vem passando por um fenômeno de reestruturação, obrigando inclusive a maior parte das empresas a uma importante redução dos custos de produção. A saturação dos grandes mercados consumidores e a queda dos preços das matérias-primas minerais transformaram a exportação de "commodities" numa fonte instável de geração de receitas e de captação de divisas principalmente para os países do Terceiro Mundo.

Em decorrência desses aspectos, diversas nações, dentre elas o Brasil, vivenciam um colapso do modelo tradicionalmente voltado para a exportação e desarticulado da dinâmica do setor industrial, pois dificilmente conseguirão colocar no mercado internacional maiores volumes de produtos minerais sem provocar uma baixa de preços.

Nesse novo cenário, as Geociências e a Tecnologia Mineral, como instrumentos de capacitação tecnológica, têm uma grande contribuição a dar ao País, dependendo do grau de articulação das políticas mineral/industrial/tecnológica. Será preciso abordar não só a problemática dos minérios e metais, mas também os desafios impostos pelos materiais concorrentes. As novas oportunidades industriais irão exigir uma capacitação tecnológica e empresarial capaz de possibilitar uma forte agregação de valor nas matérias-primas minerais e facilitar a busca de espaços no mercado internacional.

Pode-se inferir que, neste novo ambiente competitivo, poucos atores do setor mineral sobreviverão, caso não sejam adotadas algumas medidas, tais como:

- Adoção de estratégias de longo prazo: algumas indústrias, ao invés de operarem unicamente com matérias-primas tradicionais, devem incorporar novos materiais (cerâmicas, compósitos, ligas especiais etc.) em suas linhas de produtos, num esforço para assegurar e criar novos nichos tecnológicos. Este é o tratamento à ser dado aos metais de liga, aos metais especiais, aos metais menores ("minor metals") e aos minerais industriais (quartzo, caulim etc..), o que permitirá ao Brasil usufruir de inúmeros benefícios advindos de sua disponibilidade nestes minerais;

- Estabelecimento de uma diversificação seletiva: nem sempre as associações ou aquisições necessitam de grandes investimentos. Elas podem ser conduzidas adaptando-se ou compartilhando-se tecnologias de outras áreas do conhecimento. Existe sempre a possibilidade de utilização de recursos de programas de cooperação em P\&D;

- Reconhecimento de mercados: as empresas do setor mineral despendem grandes recursos buscando medidas protecionistas em lugar de adotarem novas estratégias para a sua sobrevivência, como por exemplo agregação de tecnologia, cooperação etc..

\subsection{Pesquisa \& desenvolvimento}

No tocante à incorporação de novas técnicas, o palco está montado para assistir a importantes avanços na aplicação das Geociências em várias áreas. A metalogênese, estudo da origem e distribuição espacial e temporal das concentrações ou jazidas minerais, alcançará um grande desenvolvimento através das análises mineralógicas quantitativas e dos constituintes maiores e menores das rochas. Os analisadores portáteis, como Fluorescência de Raios-X(XRF), Espectrômetros de Refletância Ótica (análise mineral), Analisadores de Fotoluminescência (AF), Métodos Eletroquímicos Refinados, Inclusões Fluidas, entre outros, permitirão o reconhecimento imediato e em ritmo compatível com as necessidades da pesquisa dos diversos materiais geológicos.

$\mathrm{O}$ aperfeiçoamento da instrumentação geofísica aérea e terrestre permitirá a obtenção e registro de quantidades crescentes de dados de maneira mais econômica e com maior poder de resolução. O uso do processamento inteligente do sinal possibilitará melhorar a performance da relação sinal/ruído.

As novas gerações de satélites orbitais terão resolução progressivamente melhor e um número maior de faixas espectrais nos seus sensores. O lançamento do Landsat7, previsto para 1994, abre a possibilidade de obtenção de imagens em 3 dimensões, bem como a instalação de um registro com resolução de 15 metros. Além da aplicação direta na elaboração e atualização de documentos cartográficos, estes satélites terão grande aplicação no planejamento urbano, análise de emissão termal dos materiais da superfície, estudos costeiros e de poluição em estuários, entre outros.

Uma outra atividade prioritária será o desenvolvimento de métodos mais econômicos de sondagem, provavelmente sem necessitar da retirada do testemunho (métodos de não amostragem), possivelmente utilizando brocas hidráulicas de alta pressão. Além disso, métodos empregando radioisótopos, como ativação neutrônica, nêutron-gama e gama-seletivo, pos- 
sibilitarão a determinação do teor dos metais diretamente nos furos.

Durante os próximos 50 anos, as reservas atualmente conhecidas de quase todos os metais e dos recursos energéticos, sofrerão um processo acelerado de esgotamento e necessitarão de um novo ciclo de reposição através de novas descobertas num ritmo nunca antes visto na história da exploração mineral.

Paralelamente, o cenário da mineração para o século XXI deverá sofrer uma alteração sensível, com certas energias, metais e materiais nãometálicos com melhor desempenho tecnológico ganhando destaque, enquanto outros perderão seu mercado através de substituição, das mudanças tecnológicas ou alteração dos padrões de consumo.

Nesse sentido, a exploração mineral deverá ser altamente refinada e aperfeiçoada. Os avanços tecnológicos dos sensores, da eletrônica, dos "scanners," dos métodos quantitativos (simulação, geoestatístico, etc.) da inteligência artificial e os programas de interpretação direta possibilitarão um acesso seletivo aos materiais geológicos, de modo a manter um suprimento de "commodities" minerais necessário à sociedade do futuro.

Uma outra componente importante do desenvolvimento das Geociências caminha em direção à resolução dos problemas inerentes da interação homem-meio físico, conforme apontado pelos programas internacionais assinalados anteriormente.

\section{CONSIDERAÇÕES FINAIS}

Os desafios em C\&T para as Geociências no Brasil nas próximas décadas são bastante complexos e podem ser resumidos em duas vertentes básicas: a primeira vinculada com a incorporação de modernas tecnologias e a segunda voltada para a geração de tecnologias próprias e do fortalecimento da base científica nacional. De um modo geral, estes dois componentes têm

\section{REFERÊNCIAS BIBLIOGRÁFICAS}

CALLOT, F. 1985 Production et consommation mondiales de minerais en 1983. Annales des Mines, n. 7/8/9, 124 p.

CONSELHO NACIONAL DE PESQUISA. 1978. Avaliação \& perspectivas. Área: Geociências. Rio de Janeiro. CNPq, vol. I, p. 131-194.

1982. Avaliação \& perspectivas. Área: Geociências. Brasília, CNPq.

COORAY, P.G. 1988. The Geosciences, international development and AGID. AGID News, p. 1-2, January. como resultante a superação dos problemas do aproveitamento racional dos recursos minerais e do conhecimento do meio físico brasileiro.

A capacidade de resolver positivamente essas questões encontra-se na diminuição das diferenças do avanço tecnológico entre as nações. Entretanto, o padrão atual de crescimento econômico, a crise da dívida, a deterioração dos termos de troca que envolvem as matérias-primas e o protecionismo dos centros industriais aumentam ainda mais esta brecha tecnológica que separa os países como o Brasil das economias avançadas. Estes problemas se agravam a cada dia em decorrência da atual conjuntura econômica adversa, que torna difícil a aquisição destas novas tecnologias. Por outro lado, as restrições externas não são irredutíveis e podem ser modificadas a partir da transformação interna (coesão das forças sociais, habilidade e aptidão do sistema sócio-político brasileiro) que fortalecerá a nossa posição negociadora.

Em contraste com a separação relativa e conjuntural no campo econômico, a "brecha" científica diminui consideravelmente, em grande parte devido à vontade de cooperação internacional dos cientistas. Este sintoma é visível na comunidade científica onde as maiores aspirações vislumbradas pelos pesquisadores, dentre eles os das Geociências, em prol do futuro da humanidade repousam na utilização racional dos recursos naturais e na preocupação crescente com o meio físico e os impactos antropogênicos no ambiente da Terra.

\section{AGRADECIMENTOS}

A realização do presente trabalho foi possível graças às informações fornecidas por vários pesquisadores, a quem o autor gostaria de agradecer sem comprometê-los: C.D.R. Carneiro (IPT, Unicamp), U.G. Cordani (IG/USP),I.G., Pacca (IAG/USP), F.F.M. de Almeida (IPT), A.M.S. Oliveira (IPT), J.P. Queiroz (FFCH/Geografia) e C.P. Ferraz (IG/Unicamp).

CORDANI, U. G.; DIAS, P. L. S. \& PACCA, I. G. 1987. Diagnóstico da pesquisa em Geociências no Estado de São Paulo. FAPESP. (Inédito).

DENGO, G. 1988. Alcances y perspectivas de las Ciencias de la Tierra en America Latina. Discurso foro comemorativo del LXX aniversario Academia de Ciencias Fisicas, Matematicas y Naturales de Venezuela, Caracas, 22 p.

DEPARTAMENTO NACIONAL DA PRODUÇÃO MINERAL. 1985. Programa: levantamentos geológicos básicos do Brasil. Convênio DNPM/CPRM, Brasília. 
DEPARTAMENTO NACIONAL DA PRODUÇÃO MINERAL 1990. Sumário mineral 1990. DNPM, Brasília, v. 10. 107p.

INTERNATIONAL UNION OF GEOLOGICAL SCIENCES. 1988. An international decade for natural hazard reduction: a summary. Washington, $40 \mathrm{p}$.

LASTRES, H. M. M. et al. 1983. Potencial científico e tecnológico do setor mineral brasileiro, CNPq, 324p.

McDIVITT, J. \& MANNERS, G. 1974. Minerals and men. Baltimore, John Hopkins University Press.

PRICE, R. 1986. Global Change: geological process, past and present. Episodes, vol. 19, n. 2, p. 91-94.
SEIBOLD, E. 1985. The Geosciences: present, past and future. Interdisciplinary Science Reviews, vol. 10, n. 1, p. 22-26.

SIBRAVA, V. 1987. The Earth Sciences in UNESCO. Episodes, vol. 10, n. 3, p. 181-186.

SOCIEDADE BRASILEIRA DE GEOLOGIA. 1982. Programa nacional de Geociências e tecnologia mineral: PRONAG. São Paulo, $\mathrm{CNPq} / \mathrm{SBG}$.

1985. Bases para uma política brasileira de pesquisa geológica básica. Comissão de Estudo do Serviço Geológico Nacional. São Paulo, 36p.

SUSLICK, S. B. et al. 1988. Recursos minerais da América do Sul. Brasil Mineral, vol. 58, p. 48-59.

Endereço do autor:

Saul B. Suslick - Universidade Estadual de Campinas - Cidade Universitária Zeferino Vaz - Distrito de Barão Geraldo - Caixa Postal 6152 - 13.081-970 - Campinas, SP - Brasil. 